\title{
La inspección de archivos: más de 150 años de servicio de transparencia de los archivos del estado español
}

ANA NASEIRO RAMUDO

Vocal de SEDIC

\begin{abstract}
Vicenta Cortés Alonso nos ha dejado recientemente dejando a la comunidad archivística con un gran vacío de grandes figuras multifacéticas que destacaron como historiadores, antropólogos, arqueólogos, conservadores, archiveros y bibliotecarios, brillantes profesionales que nacieron en el convulso siglo XIX antes de la Segunda Guerra Mundial. Vicenta fue Inspectora de Archivos en una de sus etapas finales, y aunque el cargo tenía un matiz muy diferente a sus orígenes en el momento que tomó posesión, he querido reflexionar sobre la evolución de la función inspectora en nuestra tradición archivística, a modo de pequeño homenaje y semblanza a esta excelsa profesional, que dedicó su vida a la conservación de nuestro patrimonio documental.
\end{abstract}

Inspección de Archivos, Función inspectora, Dirección General de Archivos y Bibliotecas.

\section{Introducción}

Las visitas a los archivos realizadas desde la época de Isabel I han sido fundamentales en la historia de la inspección de servicios de la Administración General del Estado. Estas visitas se realizaban no sólo a los Archivos Históricos, como cabe pensar, todos los archivos públicos, administrativos e históricos, del ámbito local o nacional, eran sometidos a dichas visitas con la finalidad de vigilar el correcto funcionamiento de sus servicios y la adecuada conservación de sus fondos documentales. La Inspección de Archivos desapareció en el Real Decreto 562/1979, de 9 de marzo, sobre funciones, organización y procedimiento de la Inspección General del Ministerio de Cultura, diluyéndose en otro organismo como era a Inspección General, que luego será sustituida por las Inspecciones Generales de Servicios, que se implementaron a nivel ministerial, autonómico, así como en diversos organismos.

La inspección de los archivos es una función de carácter especializado que requiere una formación específica a nivel profesional, normalmente, debe ser realizada por un archivero que conoce el valor de patrimonio documental como parte del patrimonio histórico, además de conocer el estado de tratamiento y conservación de los fondos documentales, sin embargo, con la legislación actual la antigua inspección de documentos y archivos de la Administración quedó totalmente desdibujada en las Inspecciones de Servicios actuales que sin bien no son incompatibles, son diferentes en cuanto a los procedimientos y finalidades del ejercicio de la 
inspección en el ámbito de la administración. Los Archivos del Estado están bajo las inspecciones de servicios ministeriales, y en ese sentido, al menos forma parte de algún tipo de intervención, aunque sea muy genérica, el problema se muestra en los archivos autonómicos, locales, y en los privados que forma parte del patrimonio documental, que han ido perdiendo a lo largo del tiempo esa visita directa que se ejercía por la inspección estatal.

La Ley de Patrimonio Histórico Español de 1985, actualmente vigente, fue un intento de cubrir esa necesidad creando instrumentos de control y sanción, sin embargo, estos se han mostrado totalmente insuficientes para evitar el deterioro y destrucción de nuestro patrimonio documental a todos los niveles. La función ejecutora en caso de ataques contra el patrimonio documental que se recoge en la Ley de Patrimonio Histórico se ha trasladado a los Cuerpos y Fuerzas de Seguridad, y la función judicial, al ámbito de los tribunales que recogen las denuncias de oficio o instancia de parte en delitos contra el patrimonio, sin embargo, no hay una función inspectora y de vigilancia periódica directa y previa que permita realmente conocer el estado real de los archivos y tomar medidas antes de que se produzca el deterioro del patrimonio, en muchos casos, la falta de ese ejercicio de control produce pérdidas inevitables en el patrimonio que cuando llegan a las autoridades ya es demasiado tarde, e incluso, en muy pocos casos no se ejerce una actividad sancionadora por las polémicas que puede conllevar la destrucción documental. Está tan alejada la legislación de la práctica que incluso en fechas más recientes La Ley 19/2013, de 9 de diciembre, de Transparencia, Acceso a la Información Pública y Buen Gobierno, que se creó con la intención de regular y garantizar el acceso a la información pública en relación a las actividades de carácter público, nació sin vincularse a los repositorios por antonomasia de la información pública garantes de la fiabilidad, integridad, autenticidad, conservación y acceso de la información contenida en la Administración, es decir, los archivos. En la actualidad existen instrumentos que se pueden aplicar en el control de la gestión de los archivos, como las auditorías internas o externas de calidad, en las que se aplica la normativa que se ha desarrollado a través de las normas ISO o UNE, que vienen a cubrir en cierto modo, la ausencia de inspecciones de archivos. Si bien, la gestión documental se contempla en múltiples normas, que afectan íntegramente la gestión, como es el caso de la 9001, existen normas específicas para la realización de auditorías en el ámbito de los archivos, como es el caso de la norma 30301, sobre requisitos a cumplir por un sistema de gestión para los documentos (SGD). En todo caso, sería interesante que los resultados de dichas auditorías fueran objeto de control por parte de los profesionales del cuerpo a niveles superiores y externos a los organismos poseedores de archivos, centralizándose en el organismo sucesor de la Inspección de Archivos u otros organismos colegiados de más reciente creación como el Consejo de Cooperación Archivística.

\section{La función inspectora de archiveros en el siglo XIX}

En 1844 Isabel I firmaba una Circular del Ministerio de Gobernación de la Península que regulaba las Comisiones Provinciales de Monumentos Históricos y Artísticos, que nació con la idea de mantener el patrimonio histórico y artístico que fue objeto en ese momento de diversas desamortizaciones. Entre sus funciones, entre otras, estaba garantizar la integridad y aumento de los archivos.

En el artículo 9 se indicaba: "Cuando en un archivo o biblioteca exista un índice o catálogo de los manuscritos o libros que en él se conservaron hasta la exclaustración de los regulares, se examinará detenidamente, se anotará la diferencia que se encontrase, y se dará parte de ello al 
Gobierno". En el artículo 10 contemplaba la salvaguarda de dicho patrimonio documental señalando: "En caso de adquirirse alguna noticia del paradero de los documentos que se hayan extraviado, se procederá con la mayor reserva y solicitud a recuperarlos, (...), poniendo en conocimiento del Gobierno las circunstancias que hayan concurrido a la usurpación o extravío de cualquier género". En el artículo 11 se regulaban los primeros instrumentos de control de dicho patrimonio: "Recogida y clasificada por épocas y materias. Los documentos, manuscritos y códices de que se habla en el art. 10 se formarán memorias en que se dé noticia del nombre y vida de los autores, se califique el mérito de cada cual, y se señalen las relaciones que puedan tener con la historia de los hechos y de las letras. Estos trabajos se remitirán directamente a la comisión central para que pueda utilizarlos como mejor convenga". Las memorias serán un documento clave para llevar a cabo la función inspectora, en el fondo documental de la Junta Facultativa se conservan la gran mayoría de las memorias.

En esta Circular incluso se implicaba a otras autoridades en el control de los fondos documentales, concretamente a los alcaldes al indicar entre sus funciones: "Retener los lienzos, códices, escrituras, estatuas y otros objetos de artes de sospechosa procedencia que se encuentren en su jurisdicción, dando parte a las comisiones para que estas acuerden lo más conveniente (...)".

A nivel Ministerial la actividad de inspección de archivos dependía de organismos internos como el Negociado de Archivo de la Secretaría de Estado y del Despacho de Estado. Y estaba encomendada en sus comienzos a la Junta Consultiva o Junta Facultativa. En el Real Decreto para la reorganización de las Bibliotecas, Archivos y Museos arqueológicos ${ }^{2}$ en el Art. 35, encontramos esta función ya encomendada a la Junta: “Los Vocales de la Junta consultiva girarán las visitas de inspección, ordinarias o extraordinarias que se nos encomienden por la Superioridad. Los reglamentos determinarán la forma y condiciones de servicio de las inspecciones de las Bibliotecas, Archivos y Museos". Dejando a un desarrollo posterior el protocolo de la visita.

En el Reglamento de Archivos, Bibliotecas y Museos de 187133, la inspección se convirtió en un elemento a tener en cuenta en la carrera administrativa porque incluso podía influir en los ascensos y se recogía en la lista de méritos en el artículo 41: "Probar inteligencia, asiduidad y celo en él servicio, acreditados por los trabajos que cada funcionario haya hecho para la formación del índice, ó por las visitas de inspección y los informes de los respectivos Jefes".

En el Capítulo VIII del Reglamento, llamado: De los Inspectores y de las visitas de inspección, en el Art. 45, correspondía a los Inspectores hacer las visitas de inspección, que les fueren encomendadas por la Dirección general de Instrucción pública, sin perjuicio de prestar sus servicios ordinarios en el establecimiento a que se hallaren adscritos. En el Art. 46. El Ministro podría encargar visitas de inspección, en casos especiales, a individuos de fuera del Cuerpo que tuviesen notoria competencia en el ramo u objeto que se trate de inspeccionar. Estas comisiones podrían recaer también en cualquier individuo del Cuerpo con la categoría de jefe. En el Art. 47, los encargados de inspecciones atenderían preferentemente a los puntos siguientes: $10^{\circ}$ La observancia de las prescripciones Reglamentarias. 2..$^{\circ}$ El cumplimiento de las respectivas instrucciones. $3 .^{\circ}$ La inteligencia, laboriosidad y celo de los empleados facultativos. $4 .^{\circ}$ La ex actitud en el servicio y la moralidad de los dependientes. $5 .^{\circ}$ Las necesidades del personal y del material. $6 .^{\circ}$ El estado de los índices que debe tener precisamente cada establecimiento. $7 .^{\circ}$ La

\footnotetext{
${ }^{1}$ Consultado en: Gaceta de Madrid, 28 de julio de 1844, n 3605.

${ }^{2}$ Consultado en: Gaceta de Madrid, 15 de junio de 1867, nº166.

${ }^{3}$ Consultado en: Revista de Archivos, Bibliotecas y Museos. n 13, 31de enero de1871, págs.193-197.
} 
exigencia en la demarcación visitada, de otros centros que puedan incorporarse a los encomendados al cuerpo, de documentos, libros u objetos antiguos o artísticos que hubieren sido encomendados por la Superioridad. En el Artículo 48, se señala de nuevo la importancia de la memoria en la inspección: "En el término de dos meses, a contar desde el día en que se finalice la visita de inspección, el encargado de ella presentará a la Dirección General de Instrucción Pública una Memoria de sus trabajos".

En el Reglamento de 1871 se reflexionaba sobre la Inspección: se señalaba que tan importante como la inspección era la necesidad de establecer unas instrucciones, donde se fijasen las reglas para los trabajos propios de cada sección del Cuerpo de Archiveros, Bibliotecarios y Museos, sin dichas reglas el autor veía inútil la inspección. Señalaba que las visitas eran importantes, sobre todo, en los lugares más aislados o lejanos, y como medida de conseguir la unidad en las tareas encomendadas al Cuerpo. Se mostraba contrario a la selección de vocales de la Junta consultiva, designados por el Gobierno para las primeras visitas, consideraba que era mejor que fueran con probados conocimientos y constante práctica en la carrera. En este sentido recoge: "Si personas verdaderamente celosas, interesadas en el aumento de las colecciones diplomáticas, bibliográficas y arqueológicas, multiplicasen en sus averiguaciones para logarlo; y la Superioridad, por su parte, al saber la existencia de libros, documentos y objetos de arte, coronaria los laudables fines que se traslucen en esa disposición, si procediese con mano fuerte a salvar tantas preciosidades ignoradas en oscuros rincones; o expuestas a segura y cercana destrucción por vituperable abandono; y por eso, no amontonándolas después en sitios inconvenientes, donde suelen continuar en falta olvido por largo tiempo, sino destinándolas desde luego a los establecimientos en que deben tener oportuna colocación para contribuir a la enseñanza del público y a la mayor ilustración de los estudiosos".

En Real Decreto de 16 de abril de 1875 de creación de la Junta Facultativa de Archivos, Bibliotecas y Museos, se establecían las bases de la futura función inspectora para los establecimientos del Cuerpo Facultativo en su artículo 90: "Examinar las Memorias y los estados que los Jefes de los establecimientos deben remitir periódicamente a la Dirección, redactando con presencia de ellos el Anuario correspondiente, en el que han de constar los servicios prestados por el Cuerpo en los establecimientos que estarán a su cargo" .

Por Orden Ministerial de 29 de mayo de 1899 se nombró la Comisión Inspectora, con el encargo de visitar los archivos, bibliotecas y museos. Esta Comisión realizaba las visitas de inspección a dichos centros, interrumpiéndose su labor en la Guerra Civil Española. El antecedente de este órgano fue La Comisión Inspectora de Catalogación que se creó por una solicitud realizada en 1897 por Vicente Vignau y Ballester, vocal de la Junta Facultativa, cuya misión era elaborar el índice central, examinar la documentación remitida por los establecimientos y los trabajos de catalogación ${ }^{4}$.

\footnotetext{
${ }^{4}$ Consultado en: Revista de Archivos, Bibliotecas y Museos. no 8-9, 1/1897, página 67.
} 


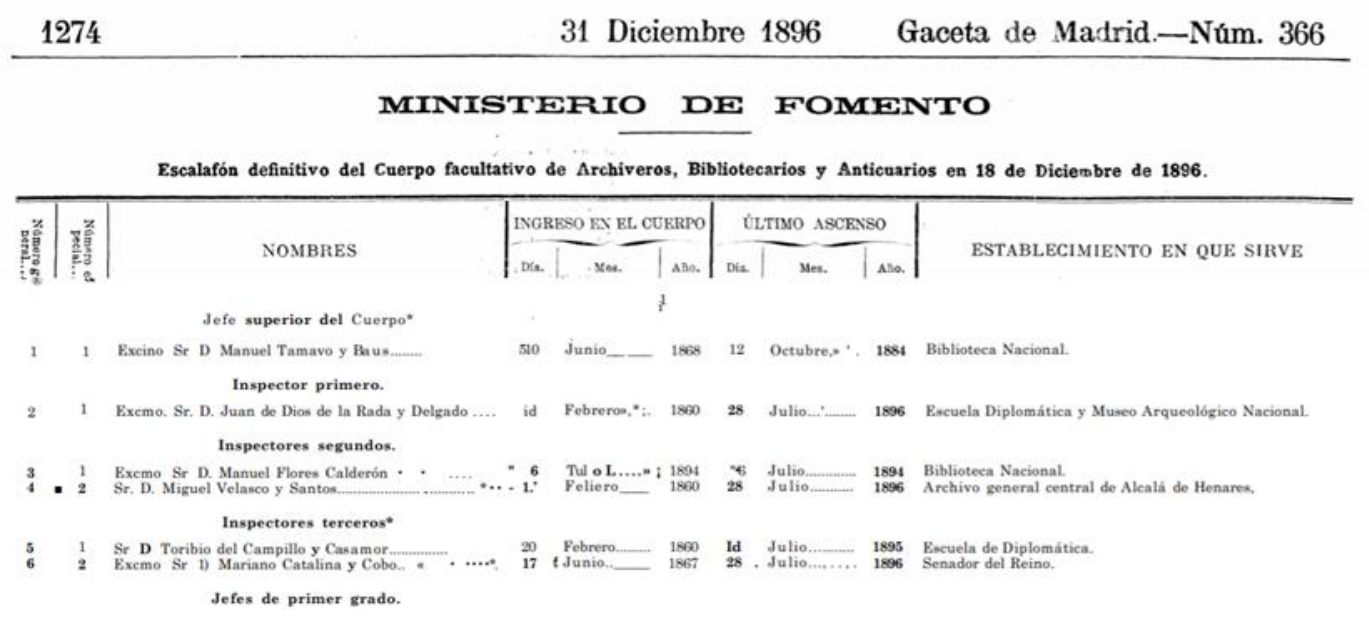

Figura 1.: Nombramientos de Inspectores publicados en la Gaceta de Madrid el 31 de diciembre 1896.

\section{La función inspectora tras el Reglamento de Archivos del Estado}

El Real Decreto 5 sobre reforma en el Cuerpo Facultativo de Archiveros, Bibliotecarios y Anticuarios de 1900, aparece recogida la inspección en el Art. 9. ${ }^{\circ}$ relativo a la Junta que se reuniría por lo menos una vez al mes, y además de las atribuciones y obligaciones que señalaba el artículo 13 del Reglamento Orgánico, y Real Decreto de $10^{\circ}$ de Junio de 1900, tendría las siguientes: encomendar inspecciones de los establecimientos a uno o varios vocales; dar cuenta a la superioridad del resultado de estas inspecciones, si fuese necesario, y proponer los premios o penas que sean de justicia; redactar cada cinco años una memoria sobre el estado de los establecimientos, con expresión de los trabajos realizados en ellos; reunir y publicar en dicha Memoria los datos estadísticos del servicio; informar al Ministerio y a la Subsecretaría, según los casos, en los expedientes de adquisición de objetos arqueológicos, diplomas y manuscritos. En el artículo 10 se establecía que en todos los establecimientos del Cuerpo habría un libro foliado y sellado de actas de visitas de inspección. Concretamente, para las que hagan los Inspectores generales, cuando les fueren encomendadas por la Subsecretaría del Ministerio, con arreglo al Art. 45 del reglamento; las que ordene el Ministerio en casos especiales en virtud del Art. 46; las que por delegación o por propia autoridad realice el Jefe superior, y las que lleve a cabo la Junta, a cuyo cometido era necesario el conocimiento del régimen, organización y trabajos de los establecimientos, de modo que habrían de consignarse por medio de acta en el libro correspondiente, detallando el resultado de la inspección.

Con el Decreto de 22 de noviembre de $1901^{6}$ por el que se aprueba el Reglamento de Archivos del Estado, concretamente, en el artículo 67, capítulo V, sobre la organización administrativa, recogen los registros, se establecían así una serie de instrumentos administrativos que van a ser básicos como elementos de revisión sobre estado de ejecución de la normativa en las visitas de Inspección: "En todos los Archivos, además de los libros de

${ }^{5}$ Consultado en: Gaceta de Madrid: no 219, de 07 de agosto de 1900.

${ }^{6}$ Consultado en: Gaceta de Madrid, no 330, de 26 de noviembre de 1901. 
Contabilidad, se llevará un registro de entrada y salida de comunicaciones oficiales, otro de las actas de la Junta de gobierno, otro de actas de visita de Inspección, otro de registro de entrada de fondos, otro de salida definitiva, otro de movimiento de fondos y otro de actas de recuento. La entrada de libros impresos con destino a la Biblioteca se registrará en un libro especial".

En 1923 por Real Orden del Ministerio de Instrucción Pública se establece un plan de visitas destinado a los archivos municipales y especiales no incorporados. En la Gaceta de Madrid de 27 de septiembre de 1924 se publicó la información de las memorias de las visitas realizadas entre 1922 y 1923. En la memoria relativa a Córdoba, José de la Torre y del Cerro, Jefe de tercer grado y del Archivo de Hacienda por aquel entonces destacaba la importancia del Archivo Municipal, donde los libros de actas capitulares que empezaban en 1479, contaba con datos interesantes para la ciudad y noticias de ilustres personajes como Cristóbal Colón, Cervantes, el Maestro Juan de Ávila, Fray Luis de Granada, Ambrosio de Morales, entre otros muchos. En la Memoria sobre Salamanca, en el Archivo de la Catedral se destacan testamentos fechados entre 1243 y 1833 , entre los más antiguos una donación que hizo Rodrigo Díaz Campeador a Don Jerónimo, Obispo de Valencia, y a su Iglesia, de muchos lugares, en el año 1098. Se destacan también los menoscabos patrimoniales en el Archivo municipal y el de la Catedral de Ciudad Rodrigo que perdieron la mayoría de sus fondos durante la invasión francesa. En general, vemos que en las memorias hay una apertura por parte de los archivos a las visitas, salvo el Archivo de la Catedral de Córdoba, que se señala que es de difícil acceso a los investigadores a pesar de su importancia. Lo mismo sucede con el Archivo de Protocolos de Salamanca donde se ponen problemas de acceso por parte del Notario sin no hay una orden específica.

En el Real Decreto relativo a la reorganización del Cuerpo de Archiveros, Bibliotecarios y Arqueólogos de 19307. Se recogen cambios en la inspección en el Art. 32: "La inspección administrativa de los servicios de los establecimientos es responsabilidad del personal del cuerpo por designación del Ministro, y podrá ser realizada por un funcionario facultativo de las cinco primeras categorías del Escalafón". Establece la posibilidad de que el Ministro pueda, además, encargar visitas de inspección, en casos especiales, a individuos de fuera del Cuerpo que tengan notoria competencia en él u objeto que se trate de inspeccionar. Además, la inspección de carácter técnico, científico o artístico se encomendará a los mismos Directores de la Biblioteca Nacional, Museo Arqueológico Nacional y Archivo Histórico Nacional, y a los Inspectores especiales técnicos según su competencia. En el Art. 18 desvincula a los inspectores especiales técnicos que no tendrán que estar adscritos a un establecimiento, aunque si dispuestos al trabajo de catalogación y su revisión científica y mantener al día todos los catálogos del Cuerpo, dirigiéndolos, inspeccionándolos y colaborando en ellos, según la especialidad de cada uno. Su residencia oficial se establece en Madrid, cuando no hayan de estar presentes por más de un mes en otra población. En Madrid tendrán su despacho en el Archivo Histórico Nacional, Biblioteca Nacional o en el Museo Arqueológico Nacional. En el Art. 9 se establecen las tipologías de inspectores técnicos especiales de: catalogación de incunables; epigrafía latina; epigrafía arábiga; diplomas de la alta Edad Media; numismática; y dos más, que se determinarían de Real Orden oída la Junta facultativa. Además, se establecía un inspector especial técnico de conservación y cuidado de papiros, pergaminos y papeles. De Real Orden se establecerían las materias análogas a las del título que quedarían incorporadas a cada una de las Inspecciones especiales. Se crean oposiciones especiales para inspectores técnicos que estarían sujetas al régimen de Cátedras universitarias.

\footnotetext{
${ }^{7}$ Consultado en: Gaceta de Madrid: no 208, de 27 de julio de 1930.
} 
Durante la Época Republicana se pasó la función encomendada a la Junta Facultativa de recogida y supervisión de los partes y memorias a los Inspectores del Cuerpo. Es posible que este traspaso fuera necesario por el relajamiento que se habían producido en épocas anteriores, concretamente durante la Dictadura de Primo de Rivera y la época anterior. Los inspectores velaron a partir de entonces por el cumplimiento de los reglamentos que se materializó con la remisión de avisos a los jefes de los establecimientos recordándoles la obligación de dar cuenta de su trabajo, para evitar sanciones posibles. La protección durante esta época se extendió a todo el patrimonio cultural, para evitar las ventas indiscriminadas en el exterior, que se recogieron en el Art. 1: "Las entidades y personas jurídicas, así eclesiásticas como civiles, no podrán enajenar inmuebles ni objetos artísticos, arqueológicos o históricos de una antigüedad que, entre los peritos en la materia, se considere, mayor de cien años, cualesquiera que sean su especie y su valor sin previo permiso del Ministerio de que dependa y mediante escritura pública". Recaía en este caso en manos de los Gobernadores su vigilancia, concretamente en el Art. 15: "Cuando por la desaparición de un objeto de su sitio habitual o por otra causa cualquiera; pueda presumirse que se intenta una enajenación, el Gobernador podrá comprobar la subsistencia del misma por inspección directa o delegada dé los inmuebles o lugares en que pudiera encontrarse, impetrando para realizarlo la oportuna autorización judicial en los casos necesarios, adoptando, si fuese preciso, las medidas precautorias del artículo 7"8.

Durante la República se creará además el Consejo Asesor como organismo complementario de la Junta Facultativa del Cuerpo de Archiveros, Bibliotecarios y Arqueólogos con el objeto de fomentar actividades en los aspectos técnicos y científicos. El Consejo elaboraría un plan de trabajos anuales aprobado por la Junta Facultativa del Cuerpo con el fin de acelerar la publicación de inventarios e índices de los fondos de cada establecimiento. El Consejo llevaría un registro de la marcha de los trabajos de los establecimientos para lo cual recibirá de los Inspectores generales los partes trimestrales y copias de las actas de los viajes de inspección?.

Todavía durante la Guerra, la Inspección General de Archivos, Bibliotecas y Museos pasará al Ministerio de Educación Nacional y se designará como inspector interino de Bibliotecas al de Archivos por el Bando Nacional ${ }^{10}$. A raíz de lo cual los jefes de los establecimientos del cuerpo de funcionarios facultativos debían de enviar los partes de trabajo reglamentarios y todas las comunicaciones sobre el asunto en la que debía intervenir la Inspección General a la Jefatura de Archivos y Biblioteca del Ministerio de Educación Nacional. Se nombró temporalmente a en sustitución de Miguel Artigas y Ferrando, como inspector general de bibliotecas.

La Inspección General del Cuerpo Facultativo de Archiveros, Bibliotecarios y Arqueólogos quedará centralizada en el Ministerio de Educación Nacional. Los Jefes de los Establecimientos servidos por los funcionarios facultativos de dicho Cuerpo enviarían los partes de trabajo reglamentarios, y todas aquellas comunicaciones sobre asuntos en que directamente deba intervenir la Inspección General, a la Jefatura de Archivos y Bibliotecas del Ministerio de Educación.

La Inspección General de Archivos, fue crucial después de la Guerra Civil, por los informes que emitían en relación con las visitas se conocía el estado en el que se encontraban los archivos

\footnotetext{
${ }^{8}$ Ley relativa a la enajenación de inmuebles, objetos artísticos, arqueológicos e históricos de una antigüedad que, entre los peritos en la materia, se considere mayor de cien años. Consultado en: Gaceta de Madrid: núm. 346, de 12 de diciembre de 1931.

${ }^{9}$ Decreto creando un Consejo Asesor como organismo complementario de la Junta facultativa del Cuerpo de Archiveros, Bibliotecarios y Arqueólogos. Consultado en: Gaceta de Madrid: nº. 6, de 06 de enero de 1933.

${ }^{10}$ Consultado en: Boletín Oficial del Estado: nº. 5, de 05 de julio de 1938.
} 
tras la contienda. En las memorias presentadas ante la inspección se detallaban los trabajos de inventariado y descripción de los fondos documentales. Tras la Guerra se reinician las labores de descripción de los fondos documentales, incluso con mayor impulso que en otras épocas dado el estado de desorganización y desconcierto en que quedaron sumidos muchos archivos, en el impulso de estos trabajos fue crucial la documentación generada en la gestión de los inspectores. El Consejo de Inspectores fue creado por Decreto de 23 de enero de 1953, estableció las Inspecciones de Zona y el Consejo de Inspectores como Órgano asesor de la Dirección General de Archivos y Bibliotecas. En dicha disposición, se fijaban las funciones del Consejo, entre las que figuraban, el estudio de las normas de carácter general referentes a los centros, a los servicios de éstos y al trabajo de los funcionarios; así como, la emisión de informes sobre los problemas que la Dirección General consideraba oportunos. Los inspectores eran nombrados entre funcionarios del Cuerpo Facultativo de más relieve y prestigio. Informaban a la Dirección General sobre la situación real de las provincias tanto de los centros como de la actitud de las autoridades con relación a los servicios de bibliotecas y archivos. Además de las Inspecciones Centrales de Archivos, Bibliotecas y Museos había seis Inspecciones de Zona de Archivos y Bibliotecas: CentroSur, Centro-Norte, Noroeste, Noroeste y Levante ${ }^{11}$. La idea era descentralizar de una única y general inspección con la creación de inspecciones de zona mediante personas formadas y responsables de zonas geográficas concretas. Conllevaba entre otras propuestas la creación de una Escuela de Biblioteconomía y Archiviología, continuadora de la Escuela Superior Diplomática. La I Reunión de Inspectores de Archivos y Bibliotecas se celebró en Madrid del 10 al 14 de abril de 1953, presidida por Joaquín Ruiz-Giménez, Ministro de Educación Nacional, los Directores Generales de Archivos y Bibliotecas, Francisco Sintes Obrador y el de Bellas Artes, Antonio Gallego Burín, el Director de la Biblioteca Nacional, Luis Morales Oliver y el General Benavides, patrono de la Biblioteca Nacional.

En la III Reunión del Consejo de Inspectores celebrada el 11 de enero de 1954, el ministro manifestó que la mejora económica obtenida para el Cuerpo de Archiveros, Bibliotecarios y Arqueólogos, era sólo el primer paso, ya que él tenía el proyecto de que los miembros de un Cuerpo cuya capacidad científica estaba sobradamente demostrada, y cuya representación social era grande, estuviesen remunerados debidamente. Tiempos diferentes a los ahora vividos corrían para el Cuerpo.

En la Zona Noreste se nombró como Inspector de Archivos al Archivero e Historiador, José María Lacarra y de Miguel. Fue alumno de Sánchez Albornoz, que le vinculó desde sus inicios al Instituto de Estudios Medievales fundado por él y Ramón Menéndez Pidal al Centro de Estudios Históricos. Allí colaboró con los proyectos entonces en marcha e igualmente fue sustituto de Sánchez Albornoz en la cátedra de Historia Medieval de la Universidad Central. Ingresó en el Cuerpo Facultativo de Archiveros, Bibliotecarios y Arqueólogos (28 de julio de 1930) con destino en el Archivo Histórico Nacional. Pocos años después fue pensionado por la Junta para la Ampliación de Estudios en París durante nueve meses (1933-1934), para ampliar sus estudios

\footnotetext{
${ }^{11}$ Cada una de estas Zonas estará constituida por las siguientes provincias:

Centro-Sur: Guadalajara, Cuenca, Albacete, Ciudad Real, Badajoz, Toledo, Cáceres y Murcia.

Centro-Norte: Santander, Salamanca, Ávila, Segovia, Valladolid, Zamora, Burgos, Palencia, Álava, Guipúzcoa y

Vizcaya.

Noroeste: Coruña, Lugo, Orense, Pontevedra, León y Asturias,

Noreste: Zaragoza, Huesca, Teruel, Soria, Logroño y Pamplona.

Levante: Barcelona, Tarragona, Gerona, Lérida, Castellón, Valencia, Alicante y Baleares.

Sin': Huelva, Sevilla, Córdoba, Cádiz, Jaén, Granada, Almería, Málaga, Marruecos y Canarias.
} 
sobre la Edad Media. Durante la Guerra Civil fue adscrito por el Gobierno Republicano a la Junta Delegada de Incautación, Protección y Salvamento del Tesoro Artístico desde el 21 de agosto de 1937 en labores de salvamento del patrimonio documental. Consiguió la cátedra de Prehistoria e Historia de España Antigua y Media e Historia de España en la Universidad de Zaragoza. Entre su numerosa producción bibliográfica destacan: sus obras de síntesis Aragón en el pasado (1960), Historia de la Edad Media (1960), Historia del reino de Navarra en la Edad Media (1976) y la monumental Historia política del reino de Navarra desde sus orígenes hasta su incorporación a Castilla (1972-1973, 3 vols.).

En la Zona del Levante se nombró como Inspector de Archivos a Jesús Martínez Ferrando. Quien ingresó el 23 de julio de 1914 en el Cuerpo Facultativo de Archiveros, Bibliotecarios y Arqueólogos, con destino en la Biblioteca Universitaria de Barcelona, para trasladarse después a la Biblioteca Provincial y Archivo de la Delegación de Hacienda de Gerona (15 de agosto de 1919) y posteriormente al Archivo de la Corona de Aragón (ACA) (1 de enero de 1920). Director accidental del ACA al estallido de la Guerra Civil en ausencia de Valls Taberner, manifestó su lealtad al Gobierno republicano y se encargó del traslado de parte de sus fondos a Viladrau para protegerlos durante la Guerra Civil. Una vez finalizada ésta, fue nombrado director (25 de enero de 1940) hasta su jubilación (enero de 1961). En este último campo se centró especialmente en el estudio de la Corona de Aragón durante los siglos XIV y XV, con notables aportaciones sobre la revolución catalana contra Juan II, los gobiernos de Pedro de Portugal y Renato de Anjou y biografías como las de Jaime II y sus hijos, o los reyes de Mallorca.

En la Zona Sur se nombró como Inspector de Archivos a José María de la Peña y de la Cámara. Tras obtener la oposición al Cuerpo de Archiveros del Estado fue destinado a la Biblioteca Nacional de España, luego se incorporó al Archivo General de Simancas, trabajo que compaginó con la licenciatura en Derecho en la Universidad vallisoletana (1925). Su interés y vinculación con la historia de América en sus trabajos de catalogación de los despachos de Indias que todavía permanecían en Simancas, le impulsaron a solicitar y obtener en 1925 el traslado al Archivo General de Indias en Sevilla. Allí llegó a ser director —interino de 1952 a 1957 y de pleno derecho hasta su jubilación en 1967-y desarrolló la mayor parte de su trabajo archivístico y de investigación, salvo un breve paréntesis en 1931 cuando estuvo destinado en la biblioteca de la Universidad de Sevilla. Como archivero destacan entre sus trabajos haber participado en el Catálogo de Pasajeros a Indias, el Catálogo de los Fondos Americanos del Archivo de Protocolos de Sevilla, el Catálogo de los Fondos Cubanos del Archivo General de Indias, la realización del Catálogo de Títulos de Indias con Ricardo Magdaleno y, en especial, la Guía del Archivo General de Indias publicada en 1958. Como investigador profundizó en sus estudios sobre Juan de Ovando (Nuevos datos sobre la visita de Juan de Ovando al Consejo de Indias, 1567-1568, 1935) Gonzalo Fernández de Oviedo (Contribuciones documentales y críticas para la biografía de Gonzalo Fernández de Oviedo, 1957), Fray Bernardo Gentile, Washington Irving o el hispanista alemán Ernesto Shaffer (1872-1946) y, en especial, sobre la figura de Cristóbal Colón (Los Restos de Cristóbal Colón, 1974).

En la Zona Centro-Sur se nombra Inspector de Archivos a Federico Navarro Franco. Ingresó en el Cuerpo Facultativo de Archiveros, Bibliotecarios y Arqueólogos en 1930 en el Archivo Histórico Nacional. En 1941 ingresó en la Junta de Intercambio y Adquisición de Libros para Bibliotecas Públicas y se le nombra Jefe de la Oficina del Depósito de Libros y Cambio Internacional de Publicaciones. En 1945 se le nombra miembro de la Comisión Central del Catálogo Bibliográfico y Documental de España. En 1954 se le nombran Secretario de la Junta 
Técnica de Archivos, Bibliotecas y Museos. Siendo ya Director del Archivo de Palacio Nacional en 1956 le nombran vocal del Patronato de Archivo Histórico Nacional.

En la Zona Centro-Norte el Inspector de Archivos a Filemón Arribas Arranz. Ingresó en el Cuerpo Facultativo de Archiveros, Bibliotecarios y Arqueólogos en 1930. En 1934 se destina al Archivo Histórico de Salamanca procedente del Archivo de Simancas y a luego a la Biblioteca de la Facultad de Medicina de Madrid. Fue nombrado en 1935 como ayudante interino del Instituto Nacional de Segunda enseñanza " Zorrilla", de Valladolid. En 1939 está destinado en el Archivo General de Simancas. En 1947 se le nombra catedrático numerario de la Universidad de Valladolid. En la Zona Noroeste se nombró como Inspector de Archivos a Gerardo Masa López, después de su ingresó en 1931 en el Cuerpo Facultativo de Archiveros, Bibliotecarios y Arqueólogos se destinó en la Biblioteca Universitaria de Valladolid, luego fue adscrito al Archivo de Hacienda de Palencia en 1932. Posteriormente fue nombrado Director del Archivo General de Simancas y luego en 1955 se nombra Director del Archivo de la Real Chancillería de Valladolid.

Como Inspector Central se nombró al Inspector general Miguel Bordonáu Mas. Quien en 1921 ingresó al Cuerpo Facultativo de Archiveros, Bibliotecarios y Arqueólogos en el Archivo General de Simancas, del que fue designado director en 1927. En 1930 pasó a la Biblioteca Nacional, de la que llegó a ser Secretario General. Fue jefe de la Biblioteca del Consejo de Estado, presidente de la Mutualidad del Cuerpo, consejero de Educación y miembro del Consejo Internacional de Archivos, entre otros organismos. Fue también Director General de Archivos y Bibliotecas (1951-1956).

Estas inspecciones se crean en el marco de: "una misión educativa y cultural que puede desarrollarse a través del funcionamiento efectivo y de la coordinación eficaz de los Archivos y Bibliotecas nacionales, provinciales y municipales, como los de carácter histórico, y la urgencia de catalogar e inventariar los fondos documentales diseminados por todo el territorio nacional en diversidad de Centros e Instituciones". El papel de las Inspecciones Regionales era funcionar como instrumento para la coordinación y dirección de actividades y servicios en directo contacto con los establecimientos comprendidos en las zonas respectivas, en cuya división territorial se adoptaban los límites en lo posible de los Distritos Universitarios.

En cada una de las demarcaciones expresadas serán encomendadas las funciones inspectoras a las personalidades de más relieve de entre los funcionarios facultativos de Archivos y Bibliotecas que presten sus servicios en Centros radicantes en cada Zona. La competencia y funciones que corresponden a los Inspectores regionales son las siguientes:

- Visitar periódicamente los establecimientos de su jurisdicción.

- Convocar reuniones de los funcionarios para darles instrucciones y estudiar los problemas comunes del servicio.

- Enviar trimestralmente a la Dirección General de Archivos y Bibliotecas partes comprensivos de los trabajos realizados por los funcionarios de su Zona y, anualmente, una Memoria con los datos estadísticos de las actividades de los Centros y cuantas circunstancias consideren oportuno recoger en la misma.

- Proponer los planes anuales de trabajo y velar por su cumplimiento

- Orientar a los funcionarios en su labor técnica.

- Proponer cuantas actividades y mejoras consideren necesarias para la buena marcha de los servicios, así como la concesión de premios y sanciones.

- Mantener contacto como representantes de la Dirección General de Archivos y Bibliotecas con las Autoridades provinciales y locales que colaboren o puedan colaborar con 
el Ministerio de Educación Nacional en la protección y estímulo de la misión de dichos Archivos y Bibliotecas.

- Mantener, asimismo, contacto con los Archivos y Bibliotecas no regidos por el Cuerpo facultativo de Archiveros, Bibliotecarios y Arqueólogos, al objeto de lograr una coordinación en las actividades y fines comunes.

- Cuantos otros cometidos y funciones se le ordenen por Superioridad ya con carácter eventual u permanente.

Los denominados inspectores generales de Archivos y Bibliotecas hasta el momento de la publicación de la Ley, pasaron a denominarse Inspectores Centrales de Archivos y Bibliotecas, con las funciones siguientes:

- Ejercían sobre los Establecimiento de Madrid (capital) idénticos cometidos a los señalados a los Inspectores Regionales sobre los Establecimientos de su demarcación.

- Quedarían a las órdenes directas de la Dirección General de Archivos y Bibliotecas, la que podrá encomendarles visitas e inspecciones extraordinarias en todo el territorio nacional.

- Reunir y clasificar los datos remitidos por las Inspecciones regionales a fin de publicar las correspondientes Memorias y Anuarios, así como emitir cuantos informes se les soliciten por la Dirección General de Archivos y Bibliotecas.

Los dos Inspectores centrales y los seis regionales de Archivos y Bibliotecas constituirán con el Inspector general de Museos el Consejo de Inspectores, que funcionará como órgano asesor de la Dirección General, de Archivos y Bibliotecas. Serán funciones del Consejo de Inspectores estudiar las normas de carácter general que se refieran a los Centros y a sus servicios y a los trabajos de los funcionarios, y la de informar sobre los problemas que la Dirección General considere oportuno someter a su consideración.

No será hasta el año 1963 cuando se creen puestos específicos dentro de la plantilla del Cuerpo de Archiveros, Bibliotecarios y Arqueólogos destinados a ejercer la función de inspector. Entre las actividades de los inspectores de archivos, se encontraba como he señalado visitar los centros archivísticos, informar sobre estos centros a la superioridad, y redactar los instrumentos de información archivísticos, como resultado final del proceso de inspección. Entre los instrumentos redactados por la Inspección se encuentra: el Censo-Guía de Archivos Españoles, la Guía de los Archivos Estatales Españoles, la Guía de Investigadores en los Archivos Españoles, las Hojas de Información Bibliográfica, ...

El Decreto 2675/1973, de 11 de octubre complementará la normativa del Ministerio de Educación y Ciencia que había regulado la Inspección Técnica de Educación y regulará las funciones de la Inspección General de Archivos y de la Inspección General de Bibliotecas, que hasta el momento se regulaba por "normas dispersas y desfasadas", tal y como señalaba el propio Decreto. Si bien la Inspección General de Archivos y la Inspección General de Bibliotecas asumían la misión inspectora en el ámbito de archivos, bibliotecas y centros de documentos, la Inspección General de Servicios tenían competencias en el ámbito de la organización y funcionamientos de todos los servicios, organismos y centros dependientes del Ministerio, incluidos los de los archivos y bibliotecas. La Inspección de Archivos y Bibliotecas ejercería sus funciones bajo de jefatura inmediata del Director General de Archivos y Bibliotecas. El Inspector general de Archivos y el Inspector general de Bibliotecas podrán recabar de todos los Centros, Organismos y Servicios en los que ejercen sus funciones inspectoras cuantos informes, documentación y antecedentes consideren necesarios para el desarrollo de sus actividades respectivas. Todas las autoridades y funcionarios, sea cual fuere su esfera de acción y 
competencia, deberán prestar ayuda y cooperación en la forma legalmente establecida a dichas Inspecciones Generales en el ejercicio de sus funciones.

Las funciones de la Inspección General de Archivos serían las siguientes:

- La inspección técnica de todos los Archivos y Servicios relacionados con los mismos, dependientes de la Dirección General de Archivos y Bibliotecas.

- La inspección técnica de aquellos otros Archivos y Servicios relacionados con los mismos, dirigidos o servidos por funcionarios de Cuerpos adscritos al Ministerio de Educación y Ciencia, sin perjuicio de las funciones inspectoras atribuidas por normas especiales a los Departamentos de que dependan, que se ejercerán en coordinación y con el asesoramiento de la Inspección General de Archivos.

- La inspección para la defensa del Tesoro Documental y Bibliográfico de la Nación.

- Velar por el cumplimiento de las Leyes, Reglamentos y demás disposiciones de carácter general relacionadas con los Servicios de Archivos en todos los Centros.

- Informar al Director General de Archivos y Bibliotecas sobre la situación de los Archivos en todos sus aspectos y proponer las medidas oportunas para corregir las deficiencias e irregularidades de orden técnico que haya podido advertir en el ejercicio de su función inspectora.

- Asesorar a la Dirección General de Archivos y Bibliotecas en los planes de mejora y ampliación de los servicios de Archivos, así como en la concesión de subvenciones que se otorguen, con cargo a sus créditos para este fin y vigilar e informar sobre la aplicación de estas últimas.

- Recoger los datos estadísticos de todos los archivos y servicios sobre los que ejerce su función inspectora, y proporcionar a los servicios correspondientes del Ministerio de Educación y Ciencia las estadísticas que precisen.

- Proponer al órgano competente, en cada caso, la apertura de expedientes por infracción de la legislación, cuyo cumplimiento están encargados de velar, dando cuenta, en su caso, al correspondiente Delegado provincial de Educación y Ciencia cuando no sea éste el destinatario de dicha propuesta.

- Estimular la actuación de los funcionarios proponiendo la concesión de recompensas que premien su dedicación y competencia profesional.

En el año de publicación del Decreto, Vicenta Cortés Alonso fue nombrada Inspectora General de Archivos, sustituía a la insigne figura de Antonio Matilla Tascón, quien fue inspector general de archivos entre 1965 y 1972, quien destacó por su Cartilla de Organización de Archivos y el impulso dado a la informatización de los Protocolos Notariales de Madrid. Vicenta ejercería su labor de inspectora hasta el año 1984, de la cual se ha destacado: el gran impulso dado a la difusión de los trabajos de los Archivo Históricos Provinciales y el emprendimiento de proyectos informáticos pioneros. Esta labor la pudo realizar debido a su carrera profesional previa: en 1959 obtuvo una beca de la Organización de Estados Americanos (OEA) para estudiar en Estados Unidos el sistema archivístico americano, siendo contratada por la Fundación Hispánica de la Biblioteca del Congreso para hacer una "Guía de los papeles hispánicos de la División de Manuscritos". También llevó a cabo labores de consultoría, como la realizada en 1971 para el gobierno de Guayaquil (Ecuador), que le encargó el proyecto de creación y organización del Archivo Histórico de Guayas. En 1972 fue consultora de la OEA en el Proyecto de Desarrollo de Archivos, que llevó por varios países. La UNESCO la nombró también asesora para el estudio de las infraestructuras archivísticas iberoamericanas, dichos informes fueron publicados por la UNESCO en la colección de estudios del Programa de Gestión de Documentos y Archivos 
(RAMP). Su labor como Inspectora, entre otros, se puede investigar en diversos archivos estatales, pero fundamentalmente, podemos acercarnos a esta figura destacada, que nos ha dejado huérfanos recientemente al dejar un vacío en la archivística que difícilmente podrá ser reemplazado debido a su labor, a sus méritos y a su fuerza, a través de su archivo personal donado por la propia facultativa al Archivo Histórico Nacional.

El Decreto número 2675, de 11 de octubre de 1979 definió en los últimos años del franquismo las funciones de la Inspección General de Archivos y de la Inspección General de Bibliotecas. Ambos organismos estaban regulados por normas dispersas y antiguas; además se encontraban supeditados a la Inspección General de Servicios del Ministerio de Educación y Ciencia y ejercían sus funciones bajo la Jefatura del Director General de Archivos y Bibliotecas. Las inspecciones ejercían un control técnico de los centros y sus servicios, para lo que podían recabar todos los informes, documentación o antecedentes que fueran necesarios, tal y como sucedía en épocas anteriores. La función de inspección se ejercía entre otros elementos archivísticos en aquellos que repercutían en la publicidad de los fondos y el grado de descripción, en este sentido, la inspección realizaba una labor no solo de vigilancia, sino también de asesoramiento; vigilaba que se cumpliesen las leyes, reglamentos y normas; se encargaba de realizar el inventario de los archivos del territorio nacional, señalaba las deficiencias en la formación de cuadros de clasificación de fondos, sistemas de archivo y su descripción para conseguir un mejor servicio; elaboraba la memoria anual y confeccionaba la estadística anual de los centros, fondos, personal y servicios, y realizaba propuestas para estimular a los funcionarios, incentivándolos con la publicación de sus trabajos

El Decreto número 562, de 9 de marzo de 1979, sobre funciones, organización y procedimiento de la Inspección General del Ministerio de Cultura, introduce un nuevo régimen sobre la actividad de los Inspectores Técnicos, y deroga en su disposición final segunda el Decreto 2675, de 11 de octubre de 1973, afectando con ello al régimen de la inspección de los servicios de archivos, en la disposición se incluía: "los fondos documentales y bibliográficos de la antigua Inspección General de Archivos que hayan sido recopilados en virtud de las funciones derogadas en la Disposición Final segunda del Real Decreto 562/1979, de 9 de marzo, se encomienda a la Subdirección General de Archivos, que los utilizará para el funcionamiento de sus servicios o los confiará a la dependencia más idónea".

\section{Procedimiento de las visitas de inspección}

El procedimiento de visita se estableció desde fechas muy tempranas tal y como vemos en la serie documental conservada en el fondo de la Junta Facultativa que recoge las visitas desde 1864. Pero será desde la década de los años veinte del siglo XX que se desarrollará de manera más regularizada.

Las visitas se aprobaban por Real Orden publicada en la Gaceta de Madrid, una vez realizadas se anotaban además en los libros de actas de los archivos. Los archivos remitían a continuación al Ministerio de Instrucción Pública y Bellas Artes un certificado del acta de la visita, como prueba de que se había realizado la visita. Estos certificados eran auténticos informes de las actividades de los archivos. A continuación de las visitas los inspectores realizaban sus memorias que remitían a la Dirección General de Bellas Artes, en las que se exponía el estado de los archivos, sus necesidades de infraestructura y personal, ... La Inspección General de Archivos remitía oficio en el que pedía información a los archivos para realizar la inspección anual, los archivos enviaban: las memorias anuales, los partes de trabajo que se enviaba periódicamente 
cada tres meses, los instrumentos de descripción, planos de los archivos y cuanta información consideraban oportuna para cubrir la demanda solicitada por el organismo central. Los partes trimestrales normalmente eran formularios que cada organismo elaboraba para enviar la información. En los informes se plantean también las necesidades del archivo en cuanto al personal, los materiales, la infraestructura, ... En los partes de trabajo se recogían tantos los trabajos de descripción, como las consultas o búsqueda de documentación, las visitas de los investigadores, la expedición de certificaciones, movimientos de entrada y salida de los fondos documentales, las instalaciones, las consultas a la biblioteca de los archivos, La Inspección General de Archivos no sólo examinaba, también establecía pautas de clasificación e inventarización de los fondos documentales, así como impulsaba la descripción de los fondos y su publicación, interviniendo directamente en la política del archivo, cuando lo consideraba oportuno. Terminada la inspección del archivo, el funcionario que se había ocupado de la inspección levantaba acta de la visita realizada.

\section{Referencias}

Ernesto Martínez Ferrando. (08-09-2021). En Real Academia Historia.

https://dbe.rah.es/biografias/39903/jesus-ernesto-martinez-ferrando

José María Lacarra. (08-09-2021). En Wikipedia.

https://es.wikipedia.org/wiki/Jos\%C3\%A9_Mar\%C3\%ADa_Lacarra

José de la Peña Cámara. (08-09-2021). En Wikipedia.

https://es.wikipedia.org/wiki/Jos\%C3\%A9_de la_Pe\%C3\%B1a_C\%C3\%A1mara

Álvarez-Coca González, María Jesús. (S/F). Vicenta Cortés Alonso y la cooperación iberoamericana. Pieza del Mes. Archivo Histórico Nacional.

Mateu Ibars, María Dolores; Mateu Ibars. Josefina (1992). Notas sobre la inspección de bibliotecas de la "zona de Levante" (1953-1968). Boletín de la ANABAD, Tomo 42, № 2, pp. 167-191.

Naseiro Ramudo, Ana (2014). La descripción archivística en la España contemporánea. Del catálogo manuscrito a los gestores web de objetos digitales culturales, Publicia, 2012.

Ministerio de Educación Nacional. Inspección General de Archivos, Bibliotecas y Museos. Archivo: Centro Documental de la Memoria Histórica. Signatura: DNSD-CORRESPONDENCIA, EXP.727.

Documentos de la Inspección General de Archivos. Archivo: Centro Documental de la Memoria Histórica. Fechas: 1979-02-15 / 1979-03-17. Signatura: DNSD-PRESIDENCIA,106,29.

Fuentes para la historia de la Inspección en el Archivo Histórico Nacional:

Secretaría de Estado y del Despacho de Estado (España) Negociado de Archivo. Fecha formación:1464 - 1848.

Contiene documentación a la inspección y organización de archivos, etc. 
Fuentes para la historia de la Inspección de Archivos en la Biblioteca Nacional de España:

Fondo documental de la Junta Facultativa de Archivos, Bibliotecas y Arqueólogos.

Comisión Inspectora de Catalogación (1897).

Libros registros de actas de visitas de inspección (desde 1900).

Visitas de Inspección (1864-1933).

Expedientes de visitas de inspección.

http://www.bne.es/es/LaBNE/Publicaciones/CatalogosBibliografiasInventarios/inventario-

junta-facultativaz.html

Fuentes para la historia de la Inspección de Archivos en el Archivo General de la Administración: Dirección General de Archivos y Bibliotecas (1924-1984). Inspección y Visitas a Archivos

Sobre la autora:

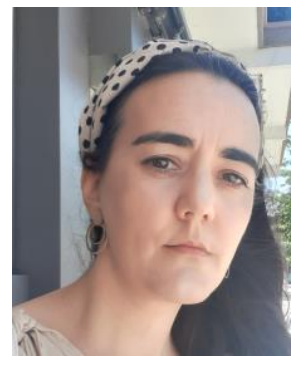

Ana Naseiro Ramudo

Facultativa de Archivos del Estado

Licenciada en Historia por la Universidad de Santiago de Compostela, ejerce de Facultativa de Archivos de la Administración General del Estado, ha trabajado en el Archivo General de la Administración del Estado como jefa de descripción y jefa de valoración y acceso. Y actualmente es la Jefa del Archivo de la Oficina Española de Patentes y Marcas. Forma parte de la Junta Directiva de SEDIC (Sociedad Española de Documentación e Información Científica), desde el año 2019, donde ejerce como vocal. E-mail: anaramudonase@gmail.com

- https://es.linkedin.com/in/ana-naseiro-ramudo-8867b676

- https://es-es.facebook.com/ana.naseiroramudo 